This item was submitted to Loughborough's Research Repository by the author.

Items in Figshare are protected by copyright, with all rights reserved, unless otherwise indicated.

\title{
Human wetness perception in relation to textile water absorption parameters under static skin contact
}

PLEASE CITE THE PUBLISHED VERSION

https://doi.org/10.1177/0040517516671127

\section{PUBLISHER}

(c) The Authors. Published by Sage.

\section{VERSION}

AM (Accepted Manuscript)

\section{PUBLISHER STATEMENT}

This work is made available according to the conditions of the Creative Commons Attribution-NonCommercialNoDerivatives 4.0 International (CC BY-NC-ND 4.0) licence. Full details of this licence are available at: https://creativecommons.org/licenses/by-nc-nd/4.0/

\section{LICENCE}

CC BY-NC-ND 4.0

\section{REPOSITORY RECORD}

Raccuglia, Margherita, S.G. Hodder, and George Havenith. 2019. "Human Wetness Perception in Relation to Textile Water Absorption Parameters Under Static Skin Contact". figshare. https://hdl.handle.net/2134/22489. 


\section{Human wetness perception in relation to textile water absorption parameters under static skin contact}

Margherita Raccuglia, Simon Hodder and George Havenith

Textile Research Journal

Accepted August 25, 2016 


\section{Abstract}

Skin-wetness-perception (WP) greatly affects thermal and sensorial discomfort in clothing and as such is of great interest to the clothing industry. Following neurophysiological studies of WP, this study looks at textile parameters affecting WP. Twenty-four fabrics, varying in thickness, fibre-type and absorption capacity were studied. Using twelve participants (males/females), the WP induced was studied in four wetness states: 1:Dry; $2: \mathrm{ABS}$, all having the same absolute water content of $2400 \mu 1$ per sample $\left(=0.024 \mu 1 \cdot \mathrm{mm}^{-2}\right) ; 3: 100 \mathrm{REL}$, saturated with water to their individual absorption capacity; $4: 50 \mathrm{REL}$, to $50 \%$ of the value in 3 . As total absorption capacity was highly correlated $(\mathrm{r}=0.99)$ to fabric thickness, condition 3 and 4 were equivalent to having the same water content per volume of textile, i.e. 0.8 and $0.4 \mu 1 \cdot \mathrm{mm}^{-3}$ respectively. Samples were applied to the upper back, statically to minimise the contribution of surface roughness/friction.

WP was highly correlated to drop in skin temperature induced by the wet fabric, and increased with application pressure of the fabric. No effect of fibre-type was observed.

In REL, with equal $\mu 1 \cdot \mathrm{mm}^{-3}$, WP showed a positive correlation to total fabric watercontent-per-area $\left(\mu 1 \cdot \mathrm{mm}^{-2}\right)$, and thus also to thickness, given the correlation between the latter two, with saturation above $1.5 \mu \mathrm{l} \cdot \mathrm{mm}^{-2}$. In ABS on the other hand, with equal $\mu 1 \cdot \mathrm{mm}^{-2}$, and thus with relative water content $\left(\mu 1 \cdot \mathrm{mm} \mu 1 \cdot \mathrm{mm}^{-3}\right)$ inversely proportional to thickness, WP was also inversely proportional to thickness. Thus WP showed opposing responses depending on the wetting type, indicating that the methodology of manipulating water content should be selected in relation to the product end-use. 
Key words: wetness perception, fabric water content, absorption capacity, fabric thickness, fabric fibre type, fabric wet weight.

\section{Introduction}

The haptic perception of wetness while wearing clothing represents one of the most critical factors contributing to thermal and sensorial discomfort during wear (Li 2001, 2005; Fukazawa and Havenith 2009). It has been acknowledged that, despite the ability to perceive wetness, the human skin is not provided with specific hygro-receptors (Clark and Edholm 1985). Therefore, the study of human wetness sensation has attracted many researchers from multiple disciplines (Bentley, 1990; Fukazawa and Havenith 2009; Ackerley et al. 2012; Bergmann Tiest et al. 2012; Filingeri and Havenith 2015). Regarding the modality in which humans perceive moisture and humidity, recently it has been proposed that the perception of wetness is based on a multimodal integration of thermal and mechanical inputs occurring at the skin, when it is wet (Filingeri et al. 2014a; Filingeri and Havenith 2015).

With regard to textile materials, which often come in contact with the human body, the level of wetness is not an intrinsic property of the material in itself, such as texture or temperature, but is defined by the combined effect of the amount of liquid present in the fabric (e.g. sweat rate, rain) and on the ability of the fabric to absorb moisture, i.e. hygroscopicity. The majority of the studies available that have investigated the mechanisms underlying the ability to perceive wetness have often neglected the 
contribution of fabric properties and our knowledge on how these modulate wetness perception is still limited. On the other hand, the study of how textile parameters affect moisture absorption has received great attention within the context of wear comfort, over the past years. Fourt et al. (1951) compared water absorption and drying properties of synthetic fabrics with conventional wool and cotton. They found that, regardless of fibre type, all fabrics absorb water and drying time is proportional to the amount of water initially absorbed, rather than related to fibre type. In support, Crow and Osczevski (1998) found that the amount of water absorbed by fabrics with different fibre type was correlated to the fabric thickness $(\mathrm{r}=0.92)$ and a strong correlation was also observed between the amount of water absorbed and the drying time $(r=0.98)$; the correlation was independent of fibre type (Crow and Osczevski, 1998). Furthermore, Yoo and Barker (2004) indicated that the total amount of liquid absorbed does not change in relation to the fibre type and the difference between fabrics with different hydroscopicity is in the rate of water absorption, rather than the total amount of water absorbed.

In wear trials, where sweat absorption occurs from the skin, Holmér (1985) observed that a clothing ensemble made of wool absorbed more sweat than a nylon one: $245 \mathrm{~g}$ versus $198 \mathrm{~g}$, respectively. This variation could be linked to differences in sweat production between the two clothing ensembles, rather than to the fibre hygroscopicity. In fact, in Holmér's study, although fabric thermal resistance and clothing insulation was very similar (and probably fabric thickness, although it was not specified) between the wool and nylon clothing system, participants presented higher sweat production in the wool condition compared to the cotton condition ( $759 \mathrm{~g}$ versus $702 \mathrm{~g}$ ), during running. 
In the past the majority of the researchers have mainly focused on comparing natural and synthetic fibre, and less on how other fabric factors affect water absorption properties and the related wetness perception. In a human sensorial trial, where fabric water content was manipulated, a wool and a polyester fabric, applied on the inner forearm, resulted in different wetness perception, despite the application of the same relative moisture levels of $0,2,4,10$ and $15 \%$ (excess of fabric conditioned weight). In particular the wool was perceived dryer than the polyester fabric at each moisture level (Li et al. 1992). In a human sensorial trial also Plant et al. (1995) studied the effect of fibre type on wetness perception by adding 4 relative levels of water $(2,4,8$ and $16 \%$ of the fabric conditioned weight, in equilibrium regain) and found that wool and cotton fibres are perceived significantly dryer than polyester. Focusing on other fabric properties, Tang et al. (2014) found that thinner fabrics are perceived significantly wetter than thicker fabrics, explaining the observed relation with fabric thickness. In this experiment, given that the same absolute amount of water was added to the experimental fabrics, thinner fabrics presented higher relative water amount to textile volume-ratios, compared to the thicker samples. The latter could have been the reason for thinner fabrics being perceived wetter. Hence, due to these thickness-related differences in fabric total water content and wetness perception, Tang's et al. (2014) results may not be applicable if a water amount relative to fabric volume (same $\mu \mathrm{l} \cdot \mathrm{mm} \mu \mathrm{l} \cdot \mathrm{mm}^{-3}$ rather than $\mu 1 \cdot \mathrm{mm}^{-2}$ ) is applied.

Against the aforementioned research background, both thickness differences and the modality in which fabric moisture content is manipulated should be taken in into account when studying fabric moisture properties and the related wetness perception. In the 
current study, in order to correct for volume-related differences in wetness perception that could occur during the application of the same absolute $\left(\mu 1 \cdot \mathrm{mm}^{-2}\right)$ water content, fabrics wetness perception was studied under the same relative to volume water content (i.e. $\mu 1$ of water per $\mathrm{mm}^{3}$ of fabric). Furthermore, in order to link the current data $\left(\mu 1 \cdot \mathrm{mm}^{-3}\right)$ to the existing literature $\left(\mu 1 \cdot \mathrm{mm}^{-2}\right)$ and ensure full comparison, a condition in which fabric samples were treated with the same absolute water amount $\left(\mu 1 \cdot \mathrm{mm}^{-2}\right)$ was included. . Additionally, the contribution of thermo- and mechano-sensitivity on the ability to discriminate various degrees of wetness in different fabrics was studied through analysis of local skin temperature changes and the impact of various fabric weights. Finally, to minimise the role of physical surface characteristics on the perception of wetness, fabrics were assessed under static contact with the skin. The aim of this study was threefold: 1 ) to examine the role of thickness and fibre type on fabric absorption capacity and wetness perception; 2) to investigate the contribution of fabric mechanical and thermal inputs on wetness perception; 3) to compare wetness perception outcomes between two different wet states, i.e. same absolute $\left(\mu 1 \cdot \mathrm{mm}^{-2}\right)$ versus same relative $\left(\mu 1 \cdot \mathrm{mm}^{-3}\right)$ water content.

\section{Methods}

\section{Specimen}

Twenty-four knitted fabric samples $(100 \times 100 \mathrm{~mm})$ selected for different structure, thickness and fibre type were included in this experiment. Details and specifications of the testing samples are summarized in table 1. 
Table 1 Details and specifications of the experimental fabrics. Data are reported as mean \pm standard deviation.

\begin{tabular}{|c|c|c|c|c|c|c|}
\hline $\begin{array}{l}\text { Fabric } \\
\text { code }\end{array}$ & Structure & Material & Thickness (mm) & Weight $\left(\mathrm{g} / \mathrm{m}^{2}\right)$ & $\begin{array}{c}100 \% \text { absorption } \\
\text { capacity }(\mu \mathrm{l})\end{array}$ & $\begin{array}{c}100 \% \text { REL } \\
\left(\mu \mathrm{l} \cdot \mathrm{mm}^{-3}\right)\end{array}$ \\
\hline F1 & single jersey & $100 \%$ cotton & $0.62 \pm 0.014$ & $140 \pm 0.012$ & $4793.3 \pm 0.495$ & 0.773 \\
\hline $\mathrm{F} 2$ & warp knit tricot (double) & $80 \%$ nylon $/ 20 \%$ elastane & $0.67 \pm 0.022$ & $190 \pm 0.006$ & $4742.0 \pm 0.566$ & 0.708 \\
\hline F3 & interlock ( $1 \mathrm{x} 1$ both sides) & $100 \%$ polyester & $1.20 \pm 0.014$ & $255 \pm 0.01$ & $8763.0 \pm 1.062$ & 0.730 \\
\hline F4 & spacer knit-3 layers (triple) & $95 \%$ polyester $/ 5 \%$ elastane & $2.80 \pm 0.005$ & $270 \pm 0.025$ & $21710.0 \pm 0.354$ & 0.775 \\
\hline F5 & double jersey & $100 \%$ cotton & $1.00 \pm 0.01$ & $280 \pm 0.037$ & $7950.7 \pm 0.566$ & 0.795 \\
\hline F6 & $2 \times 2$ rib & $97 \%$ cotton $/ 3 \%$ elastane & $1.30 \pm 0.018$ & $385 \pm 0.035$ & $9534.3 \pm 0.846$ & 0.733 \\
\hline F7 & $\begin{array}{l}\text { unbrushed, french terry } \\
\text { (tuck \& miss on reverse) }\end{array}$ & $100 \%$ cotton & $2.10 \pm 0.02$ & $330 \pm 0.001$ & $13992.7 \pm 1.556$ & 0.666 \\
\hline F8 & $\begin{array}{l}\text { brushed, french terry } \\
\text { (tuck \& miss on reverse) }\end{array}$ & $100 \%$ cotton & $3.50 \pm 0.028$ & $330 \pm 0.029$ & $24769.0 \pm 0.495$ & 0.708 \\
\hline F9 & $\begin{array}{l}\text { brushed both sides, french terry } \\
\text { (tuck \& miss on reverse) }\end{array}$ & $100 \%$ polyester & $4.00 \pm 0.037$ & $290 \pm 0.023$ & $33535.0 \pm 0.354$ & 0.838 \\
\hline F10 & $\begin{array}{l}\text { brushed both sides, french terry } \\
\text { (tuck \& miss on reverse) }\end{array}$ & $100 \%$ polyester & $1.50 \pm 0.06$ & $185 \pm 0.049$ & $11000.0 \pm 0.254$ & 0.733 \\
\hline F11 & pique (knit \& tuck) & $100 \%$ polyester & $0.60 \pm 0.058$ & $130 \pm 0.047$ & $4207.7 \pm 0.566$ & 0.701 \\
\hline $\mathrm{F} 12$ & warp knit plus brush one side & $100 \%$ polyester & $0.90 \pm 0.02$ & $130 \pm 0.023$ & $6624.7 \pm 0.778$ & 0.736 \\
\hline F13 & single jersey & $82 \%$ nylon/ $18 \%$ lycra & $0.32 \pm 0.009$ & $120 \pm 0.05$ & $2673.3 \pm 1.626$ & 0.835 \\
\hline F14 & single jersey mesh & $92 \%$ polyester $/ 8 \%$ spandex & $0.70 \pm 0.025$ & $223 \pm 0.023$ & $5828.3 \pm 1.061$ & 0.833 \\
\hline F15 & single jersey & $94 \%$ polyester $/ 6 \%$ lycra & $0.60 \pm 0.011$ & $151 \pm 0.04$ & $3535.0 \pm 0.919$ & 0.589 \\
\hline F16 & double jersey pique & $100 \%$ polyester & $0.65 \pm 0.025$ & $148 \pm 0.052$ & $5844.0 \pm 0.636$ & 0.899 \\
\hline F17 & double jersey pique & $100 \%$ polyester & $0.56 \pm 0.03$ & $160 \pm 0.095$ & $4404.0 \pm 0.495$ & 0.786 \\
\hline F18 & single jersey & $100 \%$ polyester & $0.30 \pm 0.012$ & $74 \pm 0.054$ & $2471.3 \pm 0.283$ & 0.824 \\
\hline F19 & double jersey & $100 \%$ polyester & $0.50 \pm 0.001$ & $130 \pm 0.012$ & $3954.0 \pm 0.495$ & 0.791 \\
\hline $\mathrm{F} 20$ & single jersey & $92 \%$ polyester/ $18 \%$ elastane & $0.60 \pm 0.024$ & $200 \pm 0.052$ & $4769.7 \pm 0.495$ & 0.795 \\
\hline F21 & single jersey & $\begin{array}{l}88 \% \text { polyester/ } 6 \% \text { wool } 6 \% \\
\text { spandex }\end{array}$ & $0.66 \pm 0.042$ & $192 \pm 0.09$ & $5559.3 \pm 0.283$ & 0.842 \\
\hline $\mathrm{F} 22$ & single jersey pique structure & $\begin{array}{l}83 \% \text { coolmax air } / 17 \% \\
\text { polyester }\end{array}$ & $0.60 \pm 0.01$ & $153 \pm 0.047$ & $5036.3 \pm 0.495$ & 0.839 \\
\hline F23 & single jersey & $\begin{array}{l}83 \% \text { coolmax air/ } 17 \% \\
\text { polyester }\end{array}$ & $0.56 \pm 0.023$ & $160 \pm 0.029$ & $5164.0 \pm 0.424$ & 0.922 \\
\hline F24 & double jersey & $\begin{array}{l}60 \% \text { polyester } / 40 \% \\
\text { polypropylene }\end{array}$ & $0.60 \pm 0.01$ & $142 \pm 0.029$ & $5270.3 \pm 0.849$ & 0.953 \\
\hline
\end{tabular}




\section{Wetting procedure}

Fabrics were wetted 30 min before each experimental trial, in accordance to the balanced order of application during the human sensorial assessment. Each fabric was positioned onto a plastic film and water was added by using a micropipette (SciQuip LTD, Newtown, UK) positioned at a fixed distance of $10 \mathrm{~cm}$ perpendicular to each sample and pointing at its centre. When the water was in equilibrium with the fabric, (specifically, when the water spread out uniformly across the sample; this took approximately 1 minute) each fabric was placed into a plastic bag which was securely sealed to prevent water evaporation. No water dripped from the samples inside the plastic bags during the storage period. The fabric wetting procedure was the same for all the conditions (100REL, 50REL and ABS) and only differed in the amount of added water. During the application period on the skin, each fabric was covered with a PVC film on the outer side to prevent evaporation of water.

Fabrics were tested at same relative (to volume) water content (REL; $\mu 1 \cdot \mathrm{mm}^{-3}$ ) and at same absolute water content (ABS; $\left.\mu 1 \cdot \mathrm{mm}^{-2}\right)$. Within the REL condition two different amounts of water were applied to simulate heavy and moderate sweating conditions: $100 \%$ of fabric absorption capacity (100REL) and 50\% of fabric absorption capacity (50REL), respectively. The relative water content for the 100REL condition was calculated according to:

100REL $\left(\mu l \cdot \mathrm{mm}^{-3}\right)$

$$
=100 \% \text { absorption capacity }(\mu \mathrm{l}) / \text { fabric volume }\left(\mathrm{mm}^{3}\right)
$$


The relative water content for the 50REL condition was calculated according to:

$50 \operatorname{REL}\left(\mu l \cdot \mathrm{mm}^{-3}\right)$

$$
=(100 \% \text { absorption capacity }(\mu \mathrm{l}) * 0.5) / \text { fabric volume }\left(\mathrm{mm}^{3}\right)
$$

Water absorption capacity (100\%) was determined according to the 'water absorption capacity test' described by Tang et al. (2014a). For the test a fabric sample (100 x 100 $\mathrm{mm}$ ) was put into a tank of water and 5 minutes was allowed for it to sink completely into water. Following from this, the fabric was taken out by tweezers and hung onto a rod vertically until there was no water dripping within a 30 seconds interval. The water gain was calculated according to:

Water absorbed $(\mu l)=[\operatorname{wet} F(g)-\operatorname{dry} F(g)] * 1000 \frac{\mu \mathrm{l}}{\mathrm{g}}$

Where,

wetF, is the weight of the saturated fabric $(\mathrm{g})$;

dryF, is the weight of the dry fabric $(\mathrm{g})$.

The range of fabric water absorption capacity was 2500-33500 $\mu \mathrm{l}$ (Table 1). The average amount of water per unit volume of fabrics $\left(\mu 1 \cdot \mathrm{mm}^{-3}\right)$ for both 100REL and 50REL was $0.8 \pm 0.08 \mu 1 \cdot \mathrm{mm}^{-3}($ Table 1$)$ and $0.4 \pm 0.04 \mu 1 \cdot \mathrm{mm}^{-3}$, respectively

For the ABS condition a total amount of water of $2400 \mu \mathrm{l}$ was added to all of the experimental fabrics, corresponding to $0.24 \mu 1 \cdot \mathrm{mm}^{-2}$ and translated into water content per volume to the range of $0.06-0.8 \mu 1 \cdot \mathrm{mm}^{-3}$. 
Additionally, to test whether other fabric properties, i.e. thermal conductivity or regain, could affect fabric wetness perception under the three wet states, the fabric samples were also tested under dry state (DRY). In the DRY condition 7 wet stimuli (F1, F3, F4, F8, F14, F18, F19) were included to prevent misleading responses due to the repeated presentation of the same (dry) stimulus (i.e. habituation to the stimulus).

\section{Weight differences correction}

In order to eliminate the contribution of fabric weight pressing on the skin on the perception of wetness, in the 50REL condition a subset of 7 fabrics (F1, F3, F4, F8, F14, F18, F19), wetted according to their $50 \%$ absorption capacity, were all brought to the same wet weight (50RELW ${ }_{\text {corr; }}$ same weight, different absolute water content). In order to correct for weight differences, the heaviest wet fabric (F8) of $18 \mathrm{~g}$ was chosen as reference and the remaining 6 fabrics were adjusted to this weight (18 g), by adding extra weight (layers of dry fabrics) on top (outside) of the experimental wet fabric, according to:

$$
\text { extra weight }=18 g-\text { wet fabric weight. }
$$

The extra layers of dry fabrics were separated from the experimental wet fabric trough means of a PVC film, to prevent water transfer from the wet fabric to the dry layers.

The 50RELW $\mathrm{R}_{\text {corr }}$ fabrics were also compared with the corresponding 50REL fabrics tested in standard condition (same absolute water content, different weight) (50RELnoW $\mathrm{W}_{\text {corr }}$.

Below summarised the five experimental conditions: 
100REL $=100 \%$ fabric absorption capacity $\left(0.6-0.9 \mu 1 \cdot \mathrm{mm}^{-3}\right)$.

50REL $=50 \%$ fabric absorption capacity $\left(0.3-0.45 \mu 1 \cdot \mathrm{mm}^{-3}\right)$.

$50 \mathrm{RELW}$ corr $=$ fabrics wetted according to their $50 \%$ absorption capacity, presenting different absolute water content but same total wet weight (18 g).

$\mathrm{ABS}=$ same total absolute water content $\left(2400 \mu \mathrm{l} \cdot \mathrm{mm}^{-2}\right)$;

$\mathrm{DRY}=$ equilibrium regain (no water added).

\section{Fibre type}

To study the effect of fibre type on wetness perception, 11 fabrics, matched for thickness, were grouped in three main clusters:

- Group 1 (0.60 mm): F11, F15, F20, F22, F24.

- $\quad$ Group 2 (2.10-2.80 mm): F4, F7.

- Group 3 (3.50-4 mm): F8, F9.

\section{Participants}

Twelve young (23.4 yrs. $\pm 2.4,72.4 \pm 6.4 \mathrm{Kg}, 174.57 \pm 6.9 \mathrm{~cm}$ ), active (at least 4-6 hours per week) and with no history of sensory related disorders, male (7) and female (5) participants of Western European origin, volunteered to participate in this study. The test procedure and instruments were explained to each participant verbally and through a written information form. Following from this, participants gave written informed consent for participation. Participants were not informed regarding the aim of the study,

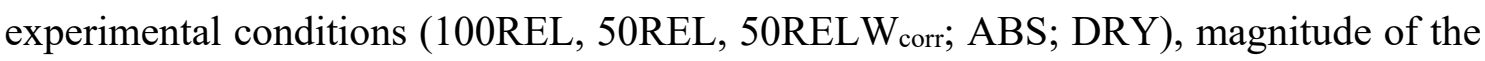


stimulus (amount of water applied) and type of fabric. The protocol and procedures involved were approved by Loughborough University Ethics Committee. The study was conducted within the confines of the World Medical Association Declaration of Helsinki for medical research using human participants.

\section{Study overview}

Fabrics were assessed in four separated trials which differed in the amount of water applied: 100REL; 50REL; ABS; DRY. Fabrics were assessed by using a quantitative sensory test, which consisted of placing, in a balanced order, 24 fabrics with different wetness levels on the upper back of each participant. Participants reported their local wetness perception, thermal sensation and thermal comfort on interval scales (see Measurements section). Prior to the first experimental trial, participants were familiarised with the experimental protocol, procedures and instruments used in the present study. The first experimental trial was conducted immediately after the familiarization session. The trials were completed in a counter balanced order and all experiments were performed in a climate controlled room, maintained at air temperature $25{ }^{\circ} \mathrm{C}$, relative humidity $50 \%$ and air velocity $<0.05 \mathrm{~m} / \mathrm{s}$.

\section{Experimental protocol}


In the four experimental trials, participants entered the controlled climatic room and lied prone on a bench wearing underwear only. A square of $100 \times 100 \mathrm{~mm}$ was marked on the upper back of each participant, with the superior margin of the square in line with the inferior margin of the seventh cervical juncture, to identify the fabrics' area of application. Before being marked, the body area was cleaned with an alcohol pad, to ensure the skin was clean and free from grease. Participants were then instrumented with skin measurement systems (see Measurements section) and rested for 20 min to allow time for skin temperature, thermal sensation and thermal comfort to stabilise. After the stabilisation period the investigator applied two reference fabrics on the participants' upper back, each corresponding to one of the two extreme points on the wetness perception scale: 0 (extremely dry) and 30 (extremely wet). The score of each reference fabric was reported by the investigator which also informed the participant that the wetness intensity of the subsequent fabrics would not exceed the range of these two references. Following from this, each experimental fabric was applied on the participants' upper back for a period of 20 seconds. To prevent evaporation of water from the fabric and related cooling during the 20 seconds stimulation period, each experimental fabric, in all conditions, was covered by a PVC film. Participants were alerted by the investigator before the application of each fabric. At the end of the 20 seconds stimulation period, participants were encouraged to verbally report their wetness perception, thermal sensation and thermal comfort for the stimulated area, using the three interval scales. The scored fabric was then removed from the upper back and a dry cloth was placed onto the tested body area to avoid any chilly sensation, consequent to the evaporation of any remaining water on the skin. The tested body area was then gently wiped with the cloth 
and dried by blowing warm air; this took approximately 1 min and allowed temperature and hydration state of the skin to return to baseline before the application of the following experimental fabric. Additionally, since the continuous application of wet stimuli may decreases one's sensitivity, $1 \mathrm{~min}$ of rest, before the subsequent fabric application also allowed the recovery of the sensory system. The same protocol was repeated for each of the 24 fabrics and each trial took approximately 2 hours. Participants were instructed to ask for a rest whenever they felt uncomfortable.

\section{Measurements}

\section{Skin temperature}

Local skin temperature, before and after the contact with the fabrics, was measured by using a single spot infrared thermometer (FLUKE 566, Fluke Corporation, USA) with a temperature range of -40 to $800{ }^{\circ} \mathrm{C}$ and an intrinsic accuracy of $\pm 1{ }^{\circ} \mathrm{C}$. During the testing the infrared thermometer was calibrated against a matte black plate whose temperature was monitored with a thermistor (Grant Instrument, Cambridge, UK) ensuring an increased accuracy of $\pm 0.2^{\circ} \mathrm{C}$.

Local skin temperature during the contact with each fabric was measured by using three fine wire Type T thermocouples (RS Components, Northants, UK) (with a response time to temperature changes lower than 0.1 second), applied on the tested body area (upper back) between the skin and the fabric. The thermocouples temperatures were monitored and recorded via a Grant Squirrel SQ2010 data logger (Grant Instrument Ltd., Cambridge, UK). Local skin temperature was calculated from the mean of the three measured spots. 
Before testing the thermocouples were calibrated by placing the measuring junction of each thermocouple in a circulating water bath whose temperature was monitored with a calibrated mercury thermometer.

Mean skin temperature was estimated from five sites, cheek, abdomen, upper arm, lower back, and back lower thigh, with iButtons wireless temperature loggers (Maxim, San Jose, USA), according to the work of Houndas and Ring (1982).

Mean Skin Temperature

$$
\begin{aligned}
& =(\text { cheek } 0.07)+(\text { abdomen } 0.175)+(\text { upper arm } 0.19) \\
& +(\text { lower back } 0.175)+(\text { back lower thigh } 0.39)
\end{aligned}
$$

\section{Wetness perception}

Based on a literature survey and extensive piloting a new ordinal wetness perception scale was developed for this study. Generally, visual analogue scales (VAS) are considered preferable when high resolution in the measurement of a particular sensation is needed. However, pilot testing for this study highlighted that the use of VAS made the scoring process difficult for the participants when a large number of stimuli (in our case 24) needed to be scored. In fact, the lack of numbers or descriptors between the two anchor points at the extremes of the VAS results in the absence of references that could be used by the participant to relate a score to the previous given scores, the latter facilitating the judgement of the next stimulus an so on. On the contrary, Likert scales have the benefit of presenting descriptors, although these types of scales are usually characterised by no more than 9 descriptors, resulting in a significantly lower resolution compared to the VAS. 
In the current study, due to the large number of wet stimuli ( 24 different wet samples) a high level of resolution was needed. This was achieved through the design of a 30 points scale. The scale ranges from 0 to 30 (Fig 1: A) and each point corresponds to a specific number. Points $0,5,10,15,20,25$ and 30 are linked to descriptors to guide the assessors during the scoring process. The criteria for the development of the scale were applied based on the results from extensive pilot testing. For instance, a number of 7 wetness descriptors was chosen based on the relatively large range of physical wetness that was added to the experimental fabrics (ABS, $50 \%$ saturated and $100 \%$ saturated). Additionally, each descriptor was divided into 5 different points to allow a gradual change from one to another descriptor and also to give to the participants the possibility to discriminate between small changes within the same descriptor.

\section{Thermal sensation}

For the same reasons presented above, a new ordinal thermal sensation scale was developed (Fig 1: B). The thermal sensation scale is a bipolar unbalanced scale presenting a central neutral point $(0=$ neutral), with 10 positive numbers (from 1 to 10 ) above and 15 negative numbers (from -1 to -15 ) below. Point 5 and 10 are linked to the thermal descriptors slightly warm and warm, respectively, whereas the negative numbers $-5,-10$ and -15 are linked to slightly cool, cool and very cool, respectively.

\section{Thermal comfort}

To assess fabrics' thermal comfort, a coarser scale was chosen, given that pilot studies for this experiment showed that the static interaction between the fabrics and skin does 
not greatly affect thermal comfort. Thermal comfort scale is a 7 point interval scale ranging from 1 to 7 with descriptors at point 1, 3, 5, 7 (Fig 1: C).

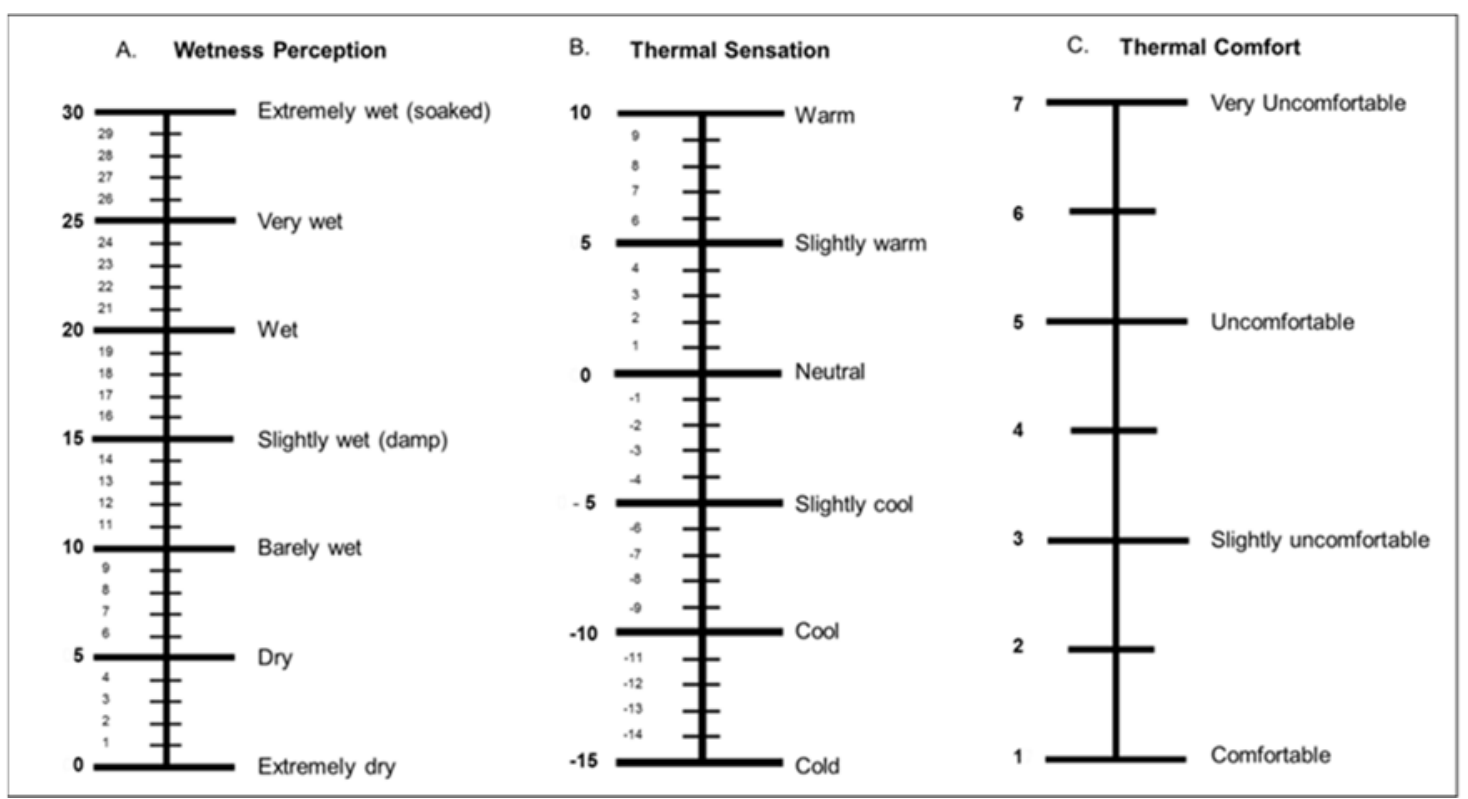

Figure 1: A Wetness Perception scale; 1: B Thermal sensation scale; 1: C Thermal Comfort scale.

\section{Statistics}

In this study the independent variables were: fabric fibre type, fabric thickness, fabric absorption capacity, fabric water content and therefore fabric wet weight. Dependent variables were: local skin temperature drop, wetness perception, thermal sensation and thermal comfort.

Data were tested for normality of distribution with Shapiro-Wilk test and Normal Q-Q plot.

Kendall Coefficient of Concordance test (Kendall's W) was conducted to assess the degree of agreement between participants (inter-judges reliability) in ranking the various experimental fabric samples. Kendall's $W$ ranges are (Fleiss et al. 2003): 
- $\quad<0.40$, poor;

- $\quad 0.40-0.59$, fair;

- $0.60-0.74$, good;

- $>0.74$, excellent.

Regression analyses were performed to study relationships between and within dependent and independent variables. Regression analyses were conducted by using data from group means.

To assess the effect of fabric fibre type on wetness perception a Friedman test was conducted for fabric group 1 (5 levels of comparison) and a Wilcoxon Signed Rank test was conducted for fabric group 2 (2 levels of comparison) and group 3 (2 levels of comparison). In group 1, when significant effects were identified, post hoc analysis was conducted by Wilcoxon Sign Tank test.

A Friedman test was also conducted to test whether there were differences in wetness perception responses within the $50 \mathrm{RELW}$ corr fabrics (fabrics corrected for weight differences). When significant effects were identified, post hoc analysis was conducted by Wilcoxon Sign Tank test. A Wilcoxon Signed Rank test was conducted to assess whether wetness perception of each fabric was significantly different between 50RELW $\mathrm{R}_{\text {corr }}$ and 50RELnoW $\mathrm{W}_{\text {corr }}$ condition.

Finally, rank analysis was performed to compare wetness perception outcomes between the two wet conditions: 50REL and ABS condition. F1, F11, F15, F20, F22, F24 
presented the same total water amount of $2400 \mu 1$ in both 50REL and ABS, therefore these fabrics were not used for the above mentioned comparison.

In all analyses $\mathrm{p}<0.05$ was used to establish significant differences. Data are reported as means \pm standard deviation (SD). Data were analysed by using the software IBM SPSS Statistics (version 22) (IBM, USA).

\section{Results}

Between participants consistency

In order to eliminate individual discrepancy, the agreement in the ranking of the wetness intensity of the experimental fabrics was examined. Kendall's $W$ for the between participants effect was 0.762 at $\mathrm{p}<0.01$, meaning that the agreement between the 12 participants was higher than it would be by coincidence and indicating excellent agreement between participants (Fleiss, 1981).

\section{Dry condition}

In one of the four experimental trials fabrics were tested under dry state (DRY), to ensure that there were no differences in fabrics wetness perception, due to other fabric properties, i.e. thermal conductivity and regain. In DRY condition fabrics were all perceived below 5 (dry) and were not significantly different $(\mathrm{p}>0.5)$.

Fabric thickness and fibre type 
Analysis of the relationship between fabric absorption capacity and fabric thickness indicated that fabric thickness accounted for the $98 \%\left(\mathrm{r}^{2}=0.98\right)$ of the variability in fabric absorption capacity, despite differences in fibre content (Fig 2: A).

Fabrics typically used for sport $\mathrm{T}$-shirts, in the thickness range of $0.30-1.00 \mathrm{~mm}$, were considered separately also. Similarly in this fabric group a strong linear relationship between fabric thickness and fabric absorption capacity $\left(\mathrm{r}^{2}=0.84\right)$ was found (Fig 2: B). 


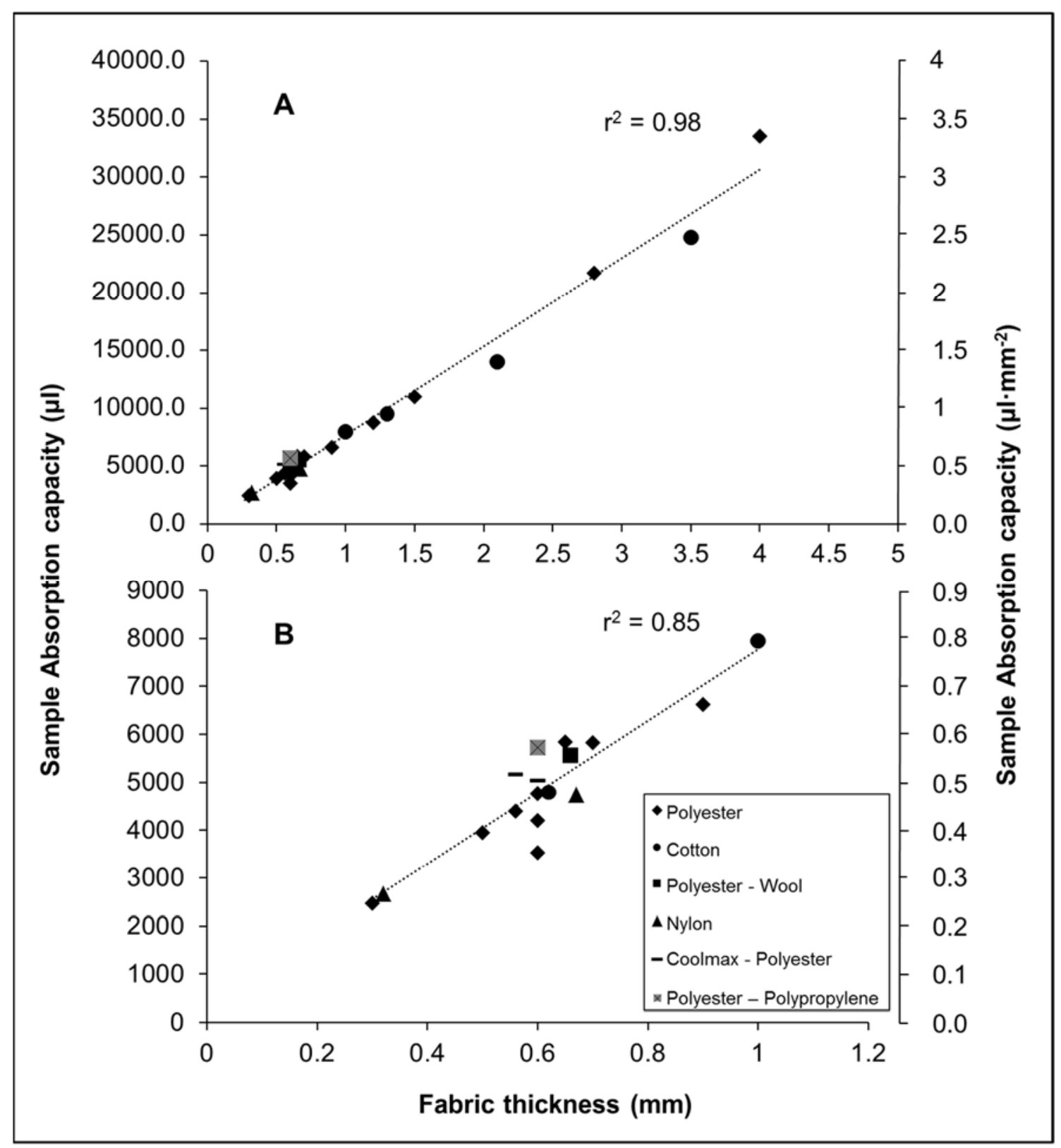

Figure 2: A Relationship between fabric absorption capacity and fabric thickness for the $100 \times 100 \mathrm{~mm}$ fabric samples. 2: B Relationship between fabric absorption capacity and fabric thickness for the fabric group characterised by a thickness range between $0.3 \mathrm{~mm}$ and $1.00 \mathrm{~mm}$.

When matched for thickness differences, different fibre types did not result in significantly different wetness perception outcomes (group $1 \mathrm{p}=0.22$; group $2 \mathrm{p}=0.47$; 
group $3 \mathrm{p}=0.32)($ Fig 3$)$. In group $1(0.60 \mathrm{~mm})$ only F15 was significantly different $(\mathrm{p}=$ 0.006) from F11, F20, F22, F24 (Fig 3).

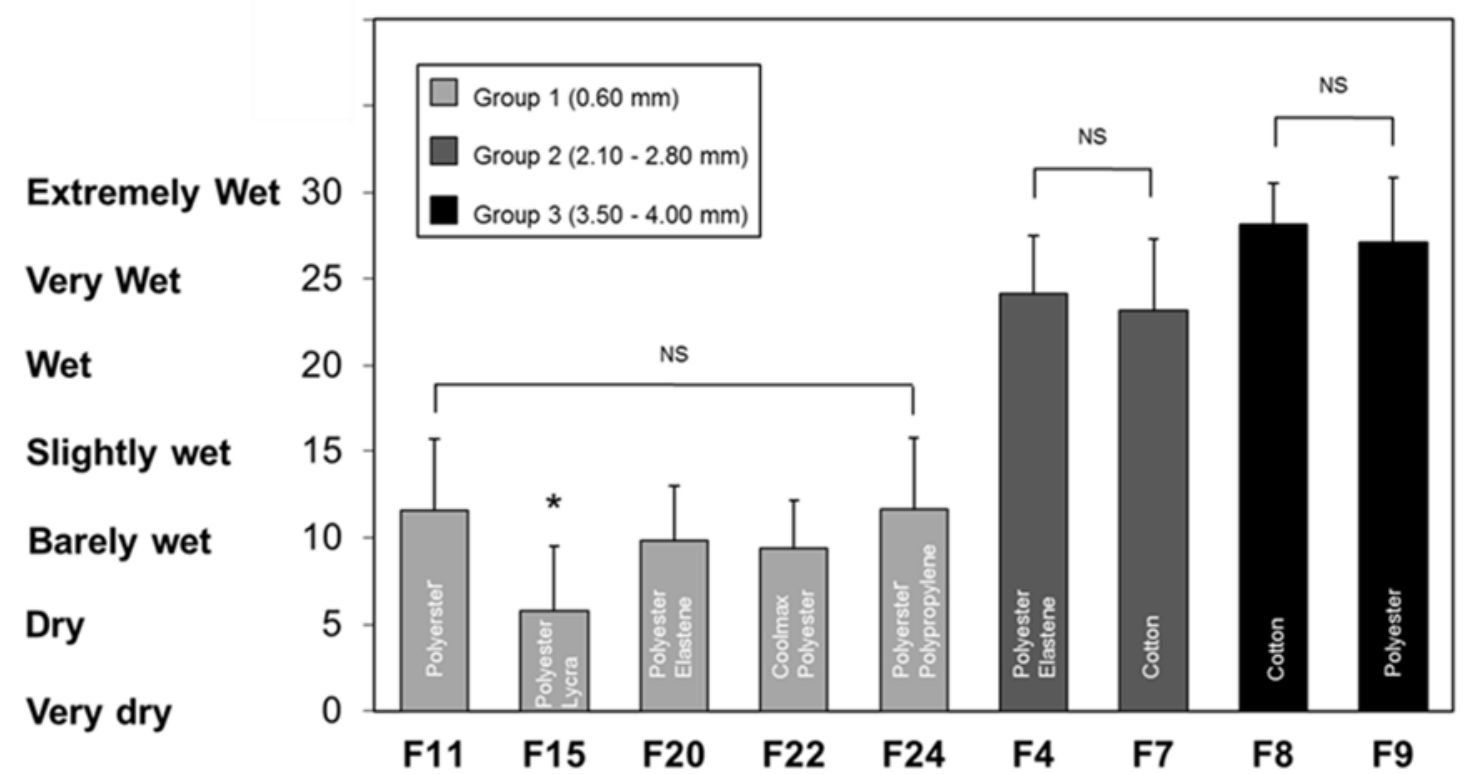

Figure 3 Effect of fibre type on wetness perception responses for the three groups of fabrics, grouped according to their thickness. There were no significant (NS) differences ( $p>0.05$ ) in wetness perception between F4 and F7 (group 2; thickness range between $2.10 \mathrm{~mm}$ and $2.80 \mathrm{~mm}$ ), between F8 and F9 (group 3; thickness range between $3.50 \mathrm{~mm}$ and $4.00 \mathrm{~mm}$ ), and between F11, F20, F22 and F24 (group 1; thickness of $0.60 \mathrm{~mm}$ ). * In group 1, F15 resulted in a significantly lower wetness perception $(p<0.05)$ compared to F11, F20, F22 and F24.

Mechanical and thermal inputs on fabric wetness perception

Wetness perception at both 100REL and 50REL was plotted against the total amount of water presented in the fabrics (Fig 4). Results indicated that wetness perception showed a strong positive relationship (non-linear, second order polynomial) with fabric total water content in both 100REL $\left(r^{2}=0.82, p<0.001\right)$ and 50REL $\left(r^{2}=0.87, p<0.001\right)$. In 100REL the regression curve shows a plateau above $15000 \mu$, suggesting a limit above which participants cannot perceive differences in fabrics water content. 


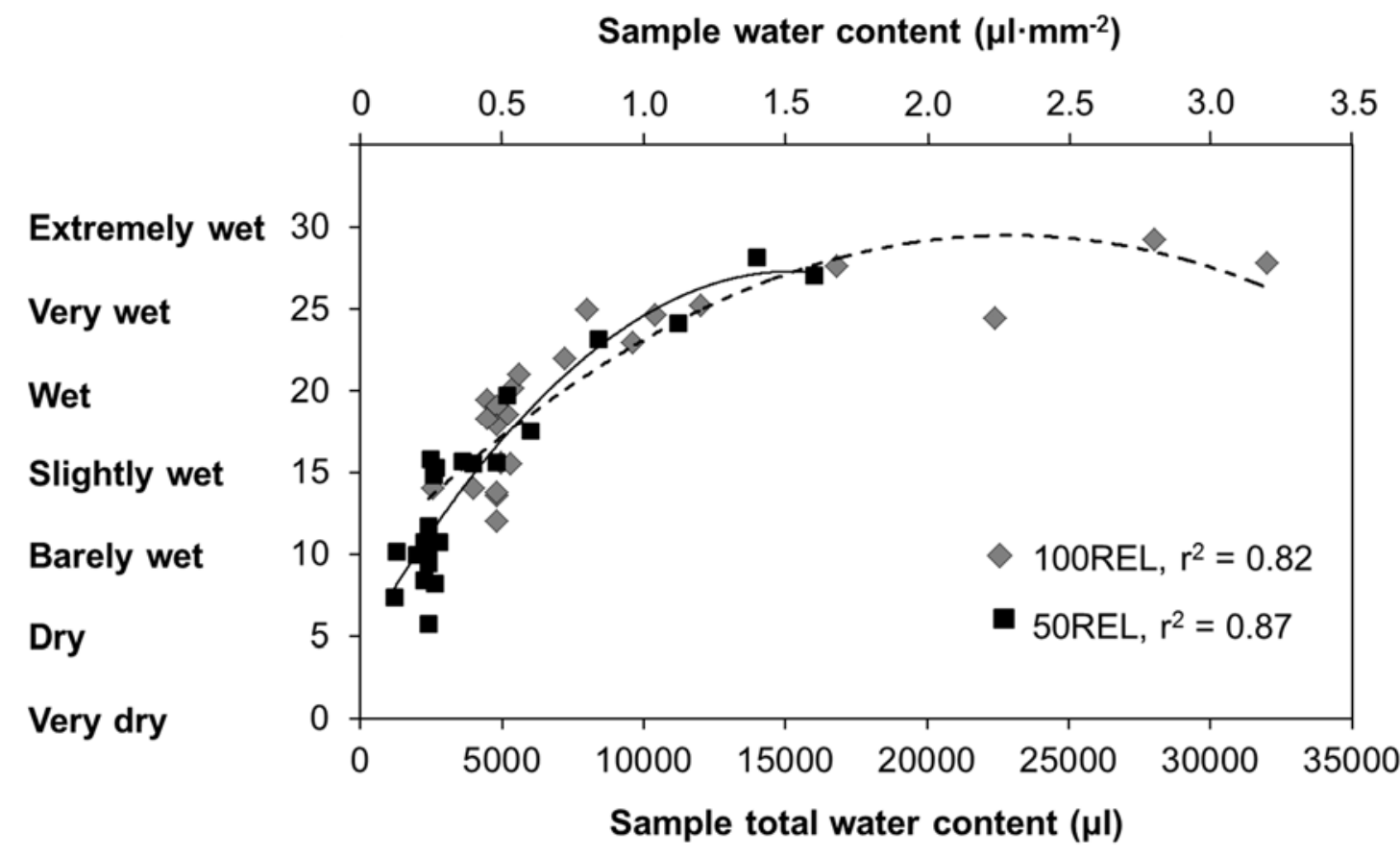

Figure 4 Relationship between fabric total water content and wetness perception in both relative experimental conditions: $100 \%$ of fabric water absorption capacity (100REL) and $50 \%$ of fabric absorption capacity (50REL). Due to the high correlation of thickness to absorption capacity, water content per volume of fabric was similar for all fabrics within each condition.

When looking at the effect of fabric weight on wetness perception the $50 \mathrm{RELno} \mathrm{W}_{\text {corr }}$ fabrics (Fig 5; grey bars; same relative water content, different absolute water content, different weight) showed the same results as in fig 4, i.e. higher wetness perception scores in fabrics with higher total water content and therefore weight $(\mathrm{p}<0.05)$. In the 50REL condition where the skin pressure for all fabrics was the same (50RELW $\mathrm{Rorr}_{\text {, }}$, achieved by correcting the weight of the fabrics to the same value as F8 (Fig 5; black bars; same relative water content, different absolute water content, same weight), different wetness perception scores were still observed $(\mathrm{p}<0.05)$, i.e. higher wetness in fabric presenting higher water content, despite same skin pressure. However, when each 50RELnoW ${ }_{\text {corr }}$ 
(lighter) fabric was compared with the corresponding 50RELW corr $_{\text {(heavier), both }}$ presenting same absolute and relative water content, the $50 \mathrm{RELW}_{\text {corr }}$ fabric was perceived always as wetter $(\mathrm{p}<0.001)$ than the 50RELnoW $\mathrm{W}_{\text {corr }}$, i.e. at same absolute and relative water content (same fabric volume) wetness perception was increased by increasing the pressure on the skin (i.e. in heavier fabrics).

As expected, F8 was not significantly different between the two conditions $(p=0.432)$, given that it was chosen as reference (same skin pressure, as well as absolute and relative water content in both 50 RELnoW $\mathrm{W}_{\text {corr }}$ and 50RELW $\left.\mathrm{R}_{\text {corr }}\right)$.

In 50RELnoW $\mathrm{W}_{\text {corr }}$ the magnitude of increase in wetness perception was related (non-linear relationship, second order polynomial, $\left.\mathrm{r}^{2}=0.8, \mathrm{p}<0.001\right)$ to the amount of added weight (skin pressure increase) (Fig 6).

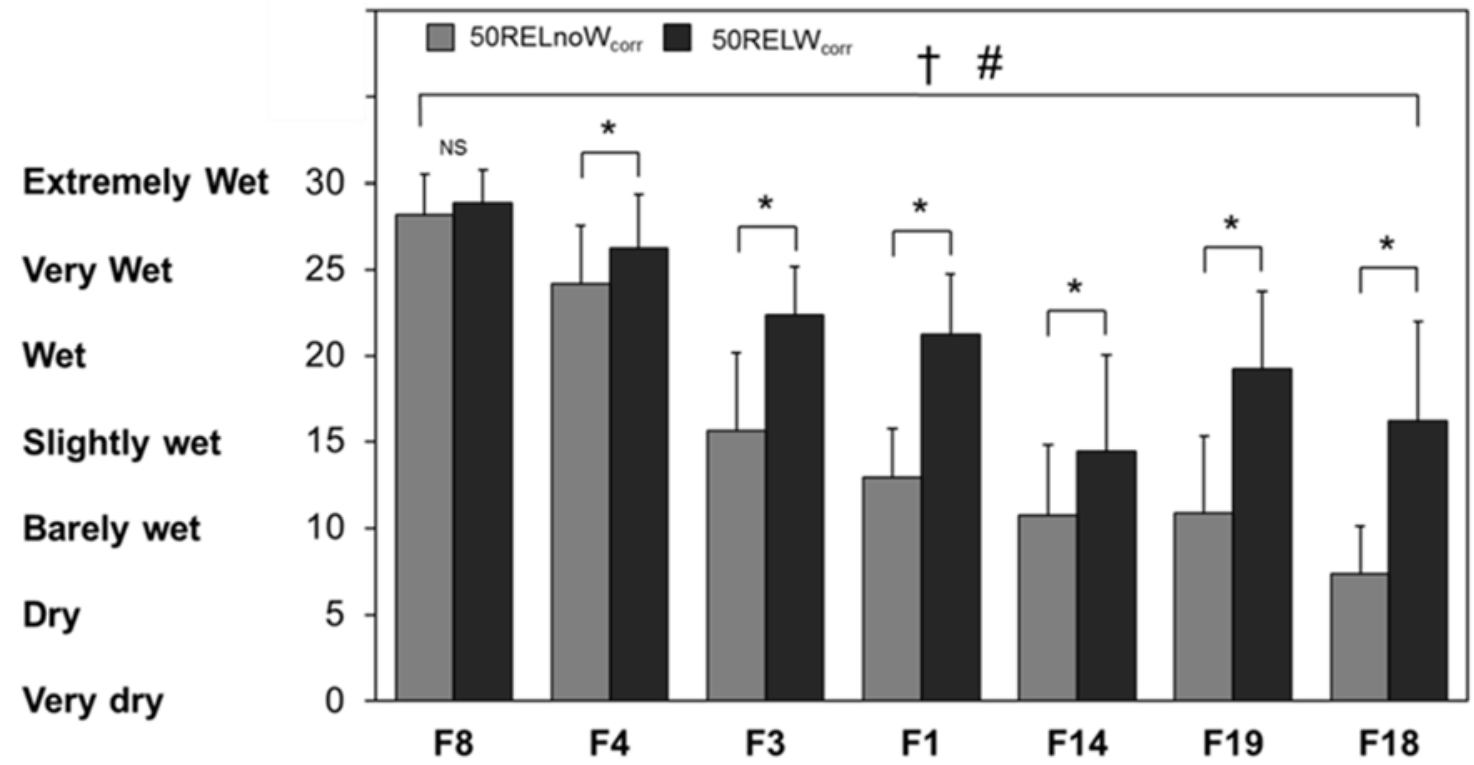

Figure 5 Fabric sorted from those containing the highest to those containing the lowest total water amount and therefore from the heaviest to the lightest fabric (F8-F18).

\# Significant differences $(p<0.05)$ in wetness perception responses between fabrics tested in standard condition (grey bars; $50 R E L n o W_{\text {corr }}$ ). 
† Significant differences $(p<0.05)$ in wetness perception responses between fabrics tested under same skin pressure (black bars; 50 RELW $W_{\text {corr }}$ ).

* Significant difference in wetness perception responses between the two skin pressure conditions $50 R E L W_{\text {corr }}$ (higher skin pressure) and 50RELnoW corr (lower skin pressure).

No significant (NS) difference in wetness perception scores between 50RELnoW corr $_{\text {and }} 50 R E L W_{\text {corr }}$ in F8 $(p=0.43)$.

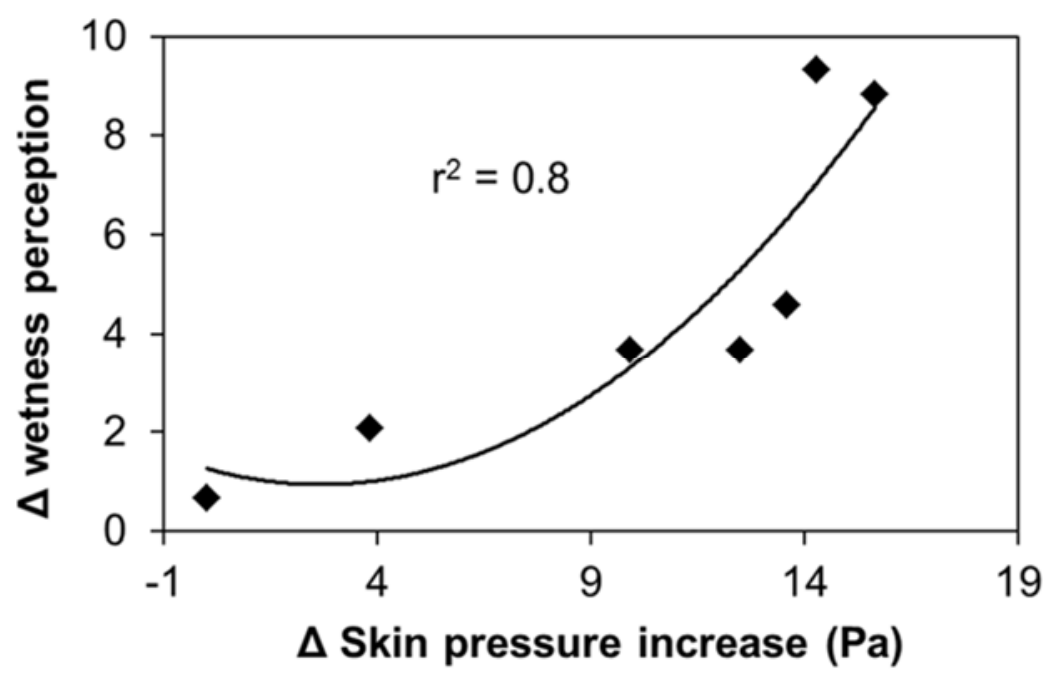

Figure 6 - Relationship between $\Delta$ Wetness perception (magnitude of increase from 50RELnoW condition) and the $\Delta$ Skin pressure increase (achieved by placing additional weight on each experimental fabrics in the 50RELW corr condition).

A non-linear (second order polynomial) relationship was found between decrease in local skin temperature (in response to the application of the wet fabrics) and fabric total water content in both 100REL $\left(r^{2}=0.74, p<0.001\right)$ and 50REL $\left(r^{2}=0.65, p<0.001\right)$ (Fig 7). The contribution of the thermal component on the perception of wetness was also indicated by the strong negative linear relationship between thermal sensation and wetness perception, in both 100REL $\left(r^{2}=0.80 ; p<0.01\right)$ and 50REL $\left(r^{2}=0.94 ; p<0.01\right)$ $($ cooler $=$ wetter $)($ Fig 8: A). 


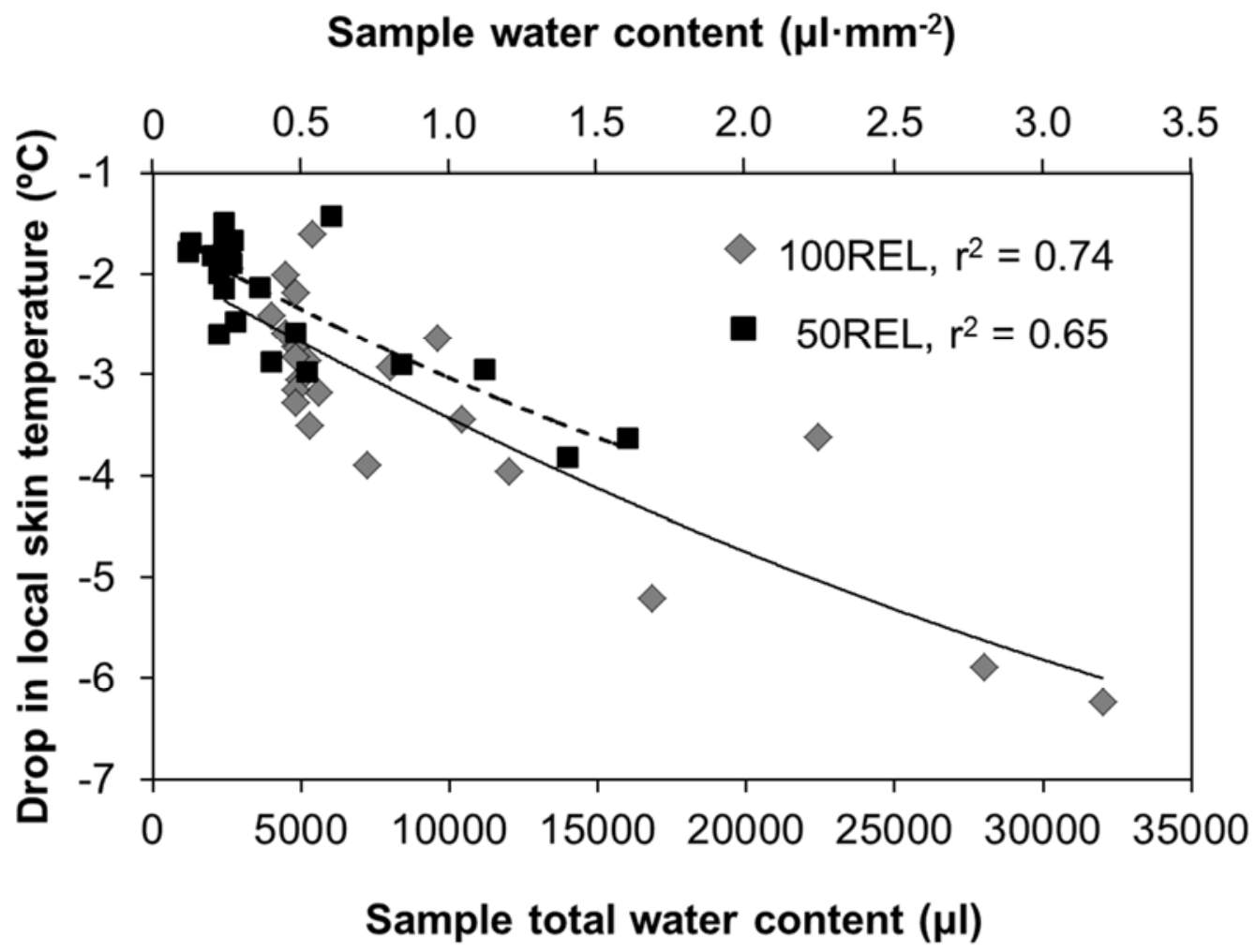

Figure 7 Relationship between fabrics total water content and decrease in local skin temperature, for both relative experimental conditions: $100 \%$ of fabric absorption capacity (100REL) and $50 \%$ of fabric absorption capacity (50REL).

Finally, a strong positive linear relationship was found between fabric wetness perception and thermal discomfort, in both 100REL $\left(r^{2}=0.86 ; p<0.01\right)$ and 50REL $\left(r^{2}=0.87 ; p<\right.$ 0.01) (Fig 8: B). 


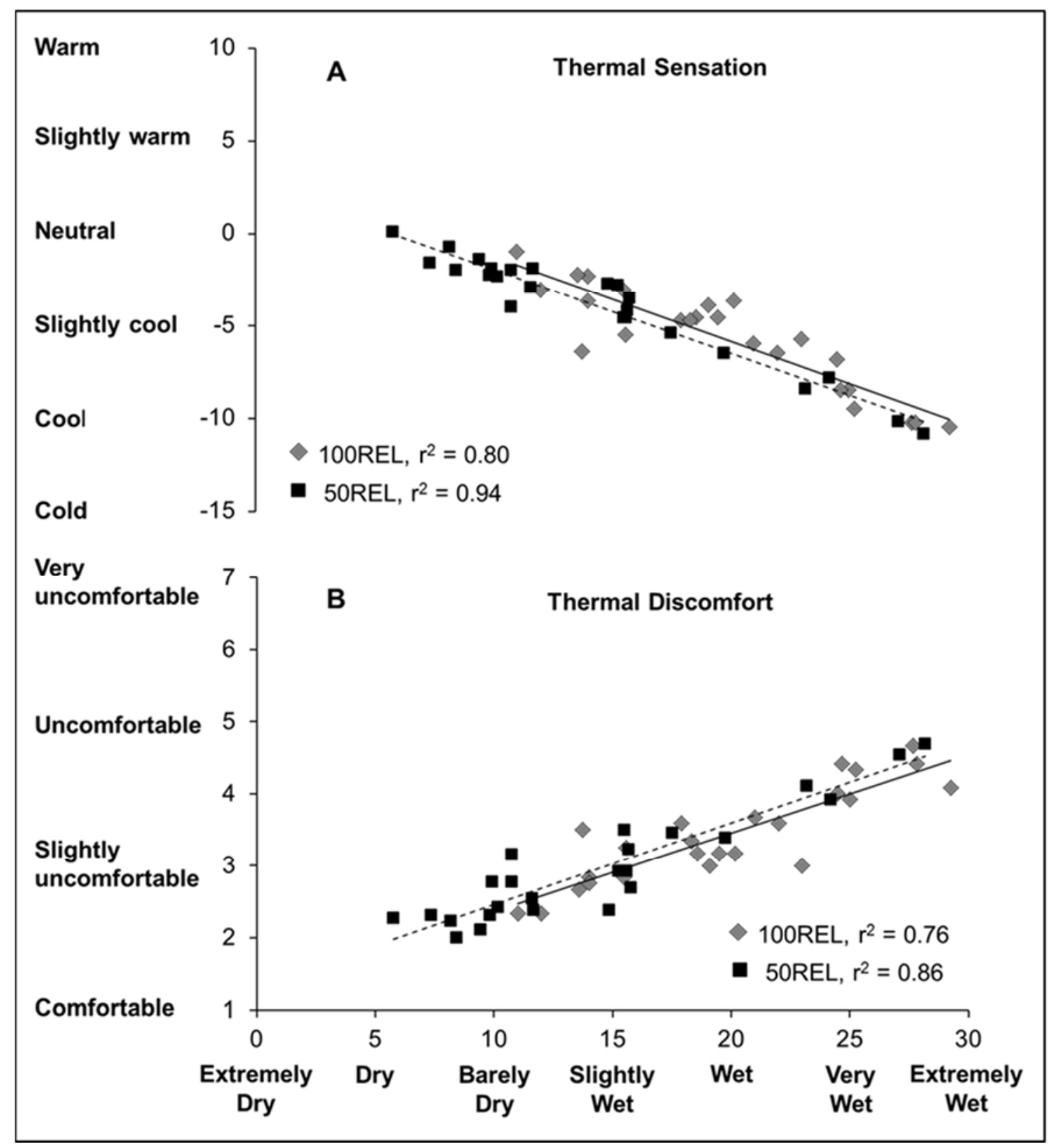

Figure 8: A Relationship between wetness perception and thermal sensation, for both relative experimental conditions: $100 \%$ of fabric absorption capacity (100REL) and $50 \%$ of fabric absorption capacity (50REL). 8: B Relationship between wetness perception and thermal discomfort, for both relative experimental conditions: $100 \%$ of fabric absorption capacity (100REL) and $50 \%$ of fabric absorption capacity (50REL).

50REL versus ABS water content 
Wetness perception scores for both 50REL and ABS fabrics were converted into rank scores, on a scale from 1 (driest) to 18 (wettest) (Fig 9). The rank analysis indicated that in 50REL thinner fabrics (and thus having the lowest total amount of water and being the lightest) were ranked as driest, whereas in ABS thinner fabrics were ranked as wettest. The latter indicates that the two conditions lead to two opposite outcomes for the same fabric, in terms of wetness perception.

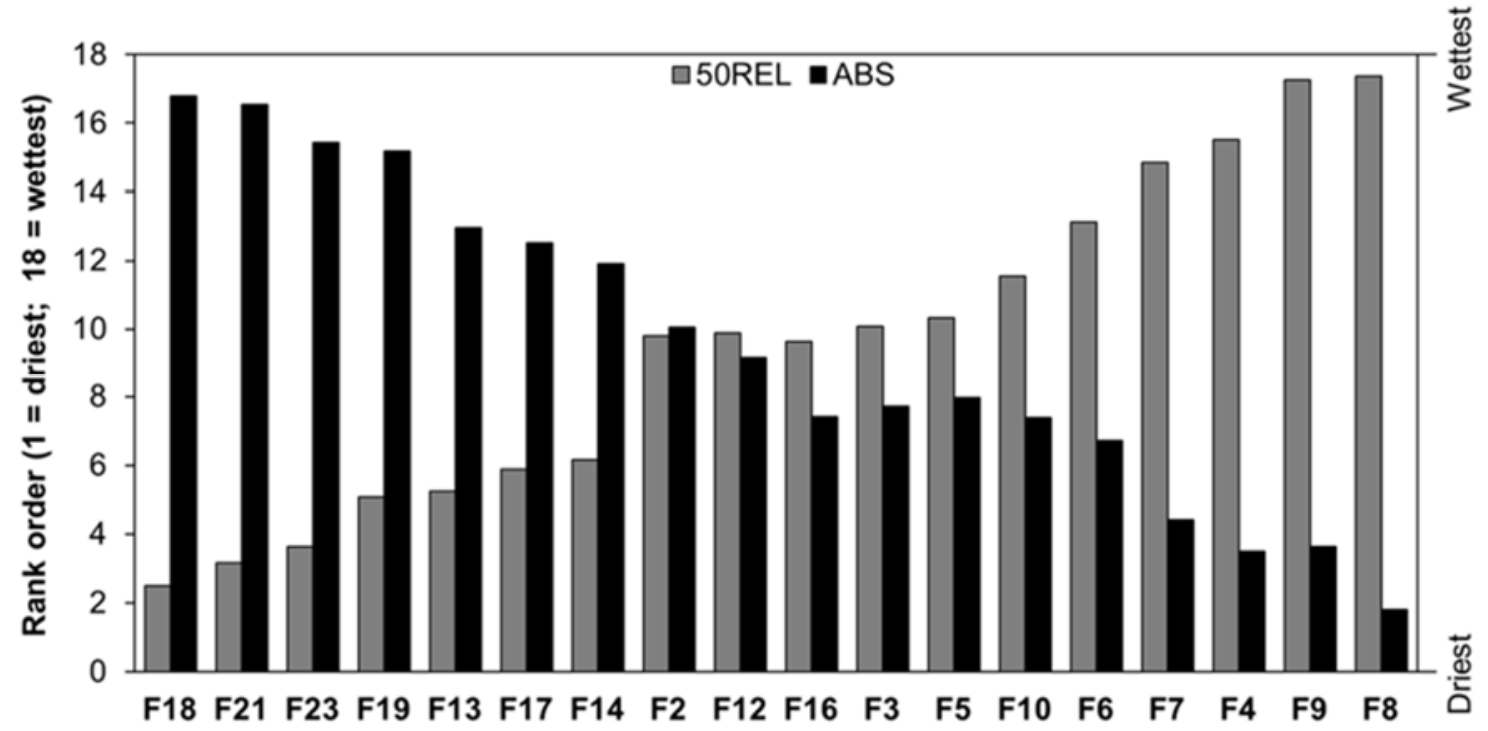

Figure 9 Rank order of wetness perception ( 0 = driest; 18 = wettest) for 18 fabrics in in both 50REL (similar $\mu \mathrm{l} \cdot \mathrm{mm}^{-3}$ ) and ABS (same $\mu \mathrm{l} \cdot \mathrm{mm}^{-2}$ ). On the $\mathrm{x}$ axis fabrics are sorted according to their rank (from driest to wettest) in 50REL.

\section{Discussion}

The present study demonstrated that fabric thickness is the major factor determining fabric absorption capacity, regardless of fibre type. Despite the absence of cutaneous 
hygro-receptors in the skin (Clark and Edholm 1985), participants were able to perceive different degrees of wetness. With regard to the contribution of textile factors on wetness perception, the results indicated that both fabric weight and cooling power provided mechanical and thermal cues. Both mechanical and thermal stimuli were determined by the total fabric water content $(\mu \mathrm{l})$ and thus indirectly by fabric thickness which should be taken into account when studying fabric wetness perception. Finally, the use of two different approaches to manipulate fabric water content, i.e. relative to volume versus absolute per surface area, lead to contrary wetness perception outcomes for the same fabric.

Fabrics wetness perception: thermal and mechanical contribution

In the REL condition, although fabrics were wetted with the same relative water amount (100\% and $50 \%$ of fabric absorption capacity), participants were still able to discriminate between the different absolute water contents. According to Filingeri et al. (2013; 2014b) wetness is primarily perceived from thermal inputs occurring at the skin, with colder stimuli giving an illusory sensation of skin wetness and with pressure having a modulating effect. In the current study higher total water content provided higher skin cooling, which was sensed as greater changes in local skin temperature by the cutaneous thermoreceptors (Campero et al. 2001) and subsequently as higher wetness. Accordingly, Li (2005), in studying wetness perception of hydrophobic sweaters worn during walking under simulated rain, found that higher dampness scores were correlated with lower skin temperature. In the current study, the contribution of thermal inputs on the perception of wetness was indicated not only by the strong relationship between wetness perception 
and drop in local skin temperature, but also between wetness sensation and thermal sensation. The strong link between wetness perception and thermal sensation was also highlighted by Niedermann and Rossi (2012) who found that some fabric samples, previously wetted, were still perceived wet after a certain period of time, despite weight measurements indicating that no moisture was present. In their study the temperature of these samples was still below room temperature, due to the earlier heat transfer through evaporation, and this lower temperature could have suggested to the participants that the fabrics were still wet. It would be interesting to study whether by controlling for heat transfer-differences, related to different water contents, humans would still be able to discriminate between different degrees of wetness.

In the current study skin cooling mainly occurred through contact, given that water evaporation was prevented. In such a condition, cooling sensation increased with the increase in fabric thickness. However, it has been indicated that the real evaporative cooling is reduced when the distance between the skin and the locus of sweat evaporation (i.e. clothing) increases (i.e. less cooling is provided to the body per gram of evaporated sweat/moisture) (Havenith et al. 2013). Following on from this principle, Wang et al., (2014) indicated a linear reduction in real evaporative cooling with the increase of the garment thickness. Therefore, it is likely that at a specific saturation level and under condition of allowed sweat evaporation, thicker fabrics would result in lower cooling sensation and wetness sensation, because sweat would evaporate further away from the skin, providing less cooling power per unit of evaporated sweat to the skin. 
In the current study results suggest that the wet weight of the fabric (mechanical stimulus) acting as load on the skin and sensed by the cutaneous mechanoreceptors (Tsunozaki and Bautista 2009), was also used by the participants as cue to perceive fabric wetness. When testing each of the 7 selected fabrics at two different skin pressures, i.e. 50RELnoW $\mathrm{W}_{\text {corr }}$

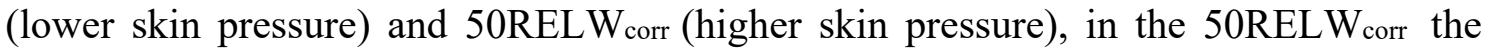
resultant higher contact pressure on the skin resulted in higher wetness perception, despite each fabric presenting the same absolute $\left(\mu 1 \cdot \mathrm{mm}^{-2}\right)$ and same relative $\left(50 \mathrm{REL} ; \mu \mathrm{l} \cdot \mathrm{mm}^{-3}\right)$ water content in both conditions (Fig 5). The latter is likely due to the higher fabric-skin contact in the higher skin pressure condition, which increased the magnitude of stimulation of both cutaneous thermo- and mechanoreceptors. The higher stimulation resulted in an 'illusory' wetter perception which suggested higher water content in heavier fabrics. The latter highlights the contribution of mechano-sensitivity in perceiving various fabric moisture contents, which is in line with the neurophysiological model of skin wetness sensitivity proposed by Filingeri et al. (2014). In practice, this would translate into the use of lightweight garments, given that greater weight on the skin elicits wetter feelings.

\section{Fabric thickness and fibre type}

The results indicated that fabric thickness/volume is the major determinant of fabric absorption capacity (Fig 2: A and B). Given the strong correlation between human's wetness perception responses and fabric water content (mainly determined by fabric thickness), fabric thickness can be considered a critical factor to take into account when studying fabric wetness perception In the present study, under static contact with the skin, 
we did not observe an effect of fabric physical surface characteristics and fabric structure, though under dynamic contact this may be different. The latter will be addressed in a future investigation.

The strong correlation between fabric water content and thickness suggests that fibre type does not play a major role for this. In support, Yoo and Barker (2004) showed that fabric fibre type only affects water absorption rate but not the total amount of liquid absorbed in equilibrium. Absorption rate might play a critical role during the initial phase of sweat production, with hydrophilic fabrics taking moisture away from the skin quicker than hydrophobic ones, therefore resulting in dryer sensations during this initial timeframe. However, when sweat production increases and both the skin and the fabric become wet, the absorption rate is likely not to affect wetness perception and comfort responses. In support, our results showed that fabrics (wetted at $50 \%$ of their absorption capacity), with different fibre types but matched for thickness (therefore total water content) did not show differences in wetness perception scores (Fig 3). The latter suggests that fibre type in itself is not a determining factor for both fabric liquid absorption capacity and related wetness perception.

Same relative versus same absolute water content

The comparison between two different approaches to manipulate fabric water content, i.e. same relative to fabric volume $\left(\mu 1 \cdot \mathrm{mm}^{-3}\right)$ versus same absolute to surface area $\left(\mu 1 \cdot \mathrm{mm}^{-2}\right)$, showed two opposite wetness perception responses for the same fabric, due to thickness/volume-related differences (Fig 9). 
The application of the same relative water content resulted in thinner fabrics being perceived dryer than the thicker ones. In fact, by applying the same relative water content, fabrics contained different total water amounts according to their volume, therefore thinner fabrics contained less water than the thicker in absolute terms. On the other hand, when applying the same absolute water amount, thicker fabrics were scored as dryer compared to thinner fabrics, given that thinner fabrics contained higher relative amounts of water to volume-ratio compared to the thicker fabrics, despite the same absolute water content (i.e. in thicker fabrics the same amount of water was spread over a larger volume).

These results indicate that the approach used to manipulate fabrics wet state should be carefully chosen with respect to the conditions to be represented. For instance, in a study assessing wetness perception of fabrics, unmatched for thickness, Tang et al. (2014) manipulated fabric wet state using an absolute water amount of $2400 \mu 1$ per $14400 \mathrm{~mm}^{2}$ $\left(0.17 \mu 1 \cdot \mathrm{mm}^{-2}\right)$. Under this wet state, thicker fabrics were perceived significantly drier than thinner fabrics (consistent with our results in ABS). Additionally, wetness perception responses where negatively correlated with fabric absorption capacity. Thus, in deciding which fabric is better (thin versus thick) for wetness perception one needs to consider the scenario of use. Results from the use of an absolute water amount may be representative of those exercise conditions that result in relatively low or mild sweat production, such as the initial phase of the work activity or relatively short-duration exercise performance. In these conditions the thinner material is likely to reach its saturation earlier than the thicker material, presenting higher relative to volume water content and higher wetness perception compared to the thinker one. Furthermore, in this scenario, according to the 
results from Tang et al. (2014) and our results in ABS, wetness perception negatively correlates with fabric absorption capacity. However, under higher sweat production conditions, e.g. when exercising in the heat or performing a prolonged exercise activity, the thicker material will also reach its saturation. In this scenario, despite the greater removal of sweat from the skin compared to the thinner material, the thicker fabric will present higher total water content, resulting in higher skin pressure and cooling capacity, both causing higher perception of wetness. Additionally, under this condition the correlation between fabric wetness perception and fabric absorption capacity will be positive, as we showed in the 100REL condition (Fig 4), rather than negative, as Tang et a. (2014) and we showed in the ABS condition. Finally, the use of a relative to volume water content may better represent post-exercise wetness perception responses, which are related to differences in fabrics drying time, mainly due to variations in fabric total water content (Crow and Osczevski 1998).

The application of the same absolute water content has led other researchers to interpret variations in fabrics wetness perception only in the light of fibre type-related differences. Niedermann and Rossi (2012), in studying the contribution of thermal cues on the ability to perceive different moisture contents, also applied the same absolute water content 2000 $\mu 1$ to three fabrics with a surface area of $2600 \mathrm{~mm}^{2}\left(0.77 \mu 1 \cdot \mathrm{mm}^{-2}\right)$, different thickness and fibre type i.e. cotton $(1.13 \mathrm{~mm})$, polyester $(0.89 \mathrm{~mm})$ and synthetic blend $(0.77 \mathrm{~mm})$. At $5 \%$ and $95 \%$ dried state the cotton fabric was perceived significantly warmer and dryer than the polyester and synthetic blend fabric. In the study this variation in wetness perception was linked by the authors to fibre type-related differences between fabrics 
(Niedermann and Rossi 2012) rather than to volume-related differences. However, based on the present data, the latter explanation (different amount of water $(\mu \mathrm{l})$ per volume $\left(\mathrm{mm}^{3}\right)$ seems more likely, given that the cotton fabric presented the highest thickness and therefore had a lower relative to volume water content.

Acknowledging the critical role of fabric thickness, it would be ideal to study wetness perception using fabrics matched for thickness characteristics. However, this is not always possible, especially in an industrial setting where comparisons of wetness perception responses of fabrics with different characteristics, thickness included, are conducted to identify the least uncomfortable material. In this situation, to prevent the introduction of biased conclusions related to differences in fabric thickness, we suggest that fabric wetness perception should be studied at both same relative to volume water content and absolute water content. The use of both approaches will allow the interpretation of the results with regards to the product application, i.e. low-mild sweat production or high sweat production activity. In addition, by taking into account the role of thickness on fabric water absorption and wetness perception, the application of relative water content to fabrics unmatched for thickness characteristics may potentially demonstrate the role (major, minor or interactive) of other factors, such fabric structure, surface geometrical features and fibre type.

Similarly, biased conclusions could be drawn when referring to threshold detection and different threshold of wetness perception in absolute terms. For instance, Sweeney and Branson (1990a) indicated that the absolute threshold of moisture detection is $0.024 \mathrm{ml}$. However, in this study always the same cotton/polyester blend fabric of $2580 \mathrm{~mm}^{2}$ was 
used to detect the threshold of $0.024 \mathrm{ml}$ of water, therefore this only applies to fabrics with a specific thickness range (not specified in their study). For instance, participants would probably not be able to detect the same amount of water of $0.024 \mathrm{ml}$ in a thicker material, or conversely would perceive a smaller amount of water in a thinner fabric, given that the fabric would contain lower or higher relative to volume water content, respectively. On the other hand, Jeon at al. (2011) indicated that when applying a total water amount of $500 \mu \mathrm{l}$ to a cotton and a high performance polyester fabric, both having a surface area of $10000 \mathrm{~mm}^{2}\left(0.05 \mu 1 \cdot \mathrm{mm}^{-2}\right)$ the different threshold (the minimum amount of water change required to elicit a difference in wetness perception from $500 \mu \mathrm{l}$ ) is 252 $\mu l$ of water for cotton and $193 \mu$ for high performance polyester. However, even in this case, the latter may not apply to wider fabric thickness/volume range.

\section{Conclusion}

In conclusion, the present study confirmed the role of fabric thickness/volume as the major determinant of fabric water absorption capacity. In particular, fabric absorption capacity increases when fabric thickness is also increased, with no effect of fibre type, although fabric absorption rate was not investigated. Given the strong positive correlation between fabric absorption capacity and wetness perception, in the static condition used, fabric thickness thus represents an important parameter to take into account when looking at wetness perception of fabrics saturated, partially saturated or presenting the same absolute water content. Under static fabric-skin contact participants can perceive various degrees of fabric wetness by integrating fabric thermal (cooling provided) and mechanical (load on the skin) inputs sensed at the skin by thermo- and mechanoreceptors, respectively. 
Fabric thermal properties under wet state seem to be the main cues contributing to the perception of moisture content. Specifically, with the increase in fabric water content the cooling power, related to the heat capacity of the liquid in the textile, also increases, resulting in higher local skin cooling and wetness perception. The contribution of fabric mechanical input was indicated by greater wetness perception in heavier fabrics, due to the resultant higher load/pressure on the skin which increases the magnitude of stimulation of both thermo- and mechanoreceptors. In practice, factors like wet weight of the fabric and resultant local skin temperature drop should be taken into account when designing a garment with reduced wetness perception and related discomfort features.

To prevent the introduction of biased conclusions, due to thickness/volume-related differences in fabric wetness perception, we suggest that the methodology used to manipulate water content of fabrics with different thickness/volume, should be carefully considered in relation to the product end-use. In particular, the use of a relative to volume water content $\left(\mu 1 \cdot \mathrm{mm}^{-3}\right)$ is recommended when evaluating fabric absorption property and related wetness perception of fabrics meant to be used for activity that induce high sweat production. In this context a saturated thick material would contain a higher total water content (due to its higher volume) with higher wetness perception compared to the thin ones. Conversely, the application of an absolute water amount better represent fabric wetness perception outcomes occurring under activities characterised by low or medium sweat production, in which the thin material will reach saturation earlier than the thick ones (due to its smaller volume), with concomitant higher wetness perception. These approaches may be particularly useful for researchers investigating wetness perception 
and discomfort-related responses between fabrics unmatched for thickness and volume characteristics with regards to the specific exercise activity to be performed.

\section{Acknowledgement}

The authors would like to acknowledge Miss Kate Riley and Professor Jinson Shen from the Textile Engineering and Materials (TEAM) Research Group, De Montfort University Leicester, for the training on fabric thickness measurement and the loan of the thickness gauge.

Conflict of interests: none. 


\section{References}

Ackerley R, Olausson H, Wessberg J, McGlone F (2012) Wetness perception across body sites. Neuroscience Letters 522:73-77.

Bentley IM (1990). The Synthetic Experiment The American Journal of Psychology Vol. 11, No. 3, pp. 405-425.

Bergmann Tiest WM, Kosters ND, Kappers AML, Daanen HAM (2012) Haptic perception of wetness. Acta psychologica 141:159-63.

Campero M, Serra J, Bostock H, Ochoa JL (2001) Slowly conducting afferents activated by innocuous low temperature in human skin. The Journal of Physiology $535: 855-865$.

Clark R, Edholm O (1985) Man and His Thermal Environment. London: E. Arnold.

Crow RM, Osczevski RJ (1998) The Interaction of Water with Fabrics. Textile Research Journal 68:280-288.

Filingeri D, Fournet D, Hodder S, Havenith G (2014a) Why wet feels wet? A neurophysiological model of human cutaneous wetness sensitivity. Journal of neurophysiology 112:1457-69.

Filingeri D, Havenith G (2015) Human skin wetness perception: psychophysical and neurophysiological bases. Temperature 2:86-104.

Filingeri D, Redortier B, Hodder S, Havenith G (2014b) Thermal and tactile interactions 
in the perception of local skin wetness at rest and during exercise in thermo-neutral and warm environments. Neuroscience 258:121-30.

Filingeri D, Redortier B, Hodder S, Havenith G (2013) The role of decreasing contact temperatures and skin cooling in the perception of skin wetness. Neuroscience letters 551:65-9.

Fleiss JL, Levin B, Cho Paik M (2003) Statistical Methods for Rates and Proportions, 3rd Editio. Wiley Series In Probability and Statistics

Fourt L, Sookne AM, Frishman D, Harris M (1951) The Rate of Drying of Fabrics. Textile Research Journal 21:26-33.

Fukazawa T, Havenith G (2009) Differences in comfort perception in relation to local and whole body skin wettedness. European journal of applied physiology 106:1524.

Havenith G, Bröde P, den Hartog E, et al (2013) Evaporative cooling: effective latent heat of evaporation in relation to evaporation distance from the skin. Journal of applied physiology 114:778-85.

Holmer I (1985) Heat Exchange and Thermal Insulation Compared in Woolen and Nylon Garments During Wear Trials. Textile Research Journal 55:511-518.

Houndas Y, Ring E (1982) Human body temperature - Its measurement and regulation. Plenum Press, New York, NY.

Li Y (2005) Perceptions of temperature, moisture and comfort in clothing during 
environmental transients. Ergonomics 48:234-48.

Li Y (2001) The science of clothing comfort. Textile Progress 31:1-135.

Li Y, Plante AM, Holcombe B V (1992) The physical mechanisms of the perception of dampness in fabrics. The Annals of physiological anthropology 11:631-4.

Niedermann R, Rossi RM (2012) Objective and subjective evaluation of the human thermal sensation of wet fabrics. Textile Research Journal 82:374-384.

Plante AM, Holcombe BV, Stephens LG (1995) Fiber Hygroscopicity and Perceptions of Dampness: Part I: Subjective Trials. Textile Research Journal 65:293-298.

Tang KPM, Kan CW, Fan JT (2014) Assessing and predicting the subjective wetness sensation of textiles: subjective and objective evaluation. Textile Research Journal $85: 838-849$.

Tsunozaki M, Bautista DM (2009) Mammalian somatosensory mechanotransduction. Current opinion in neurobiology 19:362-9.

Yoo S, Barker RL (2004) Moisture Management Properties of Heat-Resistant Workwear Fabrics-- Effects of Hydrophilic Finishes and Hygroscopic Fiber Blends. Textile Research Journal 74:995-1000. 